\title{
Regulation of IL-2 gene expression by Siva and FOXP3 in human T cells
}

Virginia K Hench ${ }^{1,2}$ and Lishan Su $\mathrm{Su}^{1,2,3^{*}}$

\begin{abstract}
Background: Severe autoinflammatory diseases are associated with mutations in the Foxp3 locus in both mice and humans. Foxp3 is required for the development, function, and maintenance of regulatory $T$ cells $\left(T_{\text {regs }}\right)$, a subset of CD4 cells that suppress T cell activation and inflammatory processes. Siva is a pro-apoptotic gene that is expressed across a range of tissues, including CD4 T cells. Siva interacts with three tumor necrosis factor receptor (TNFR) family members that are constitutively expressed on $T_{\text {reg }}$ cells: CD27, GITR, and OX40.

Results: Here we report a biophysical interaction between FOXP3 and Siva. We mapped the interaction domains to Siva's C-terminus and to a central region of FOXP3. We showed that Siva repressed IL-2 induction by suppressing $I L-2$ promoter activity during $T$ cell activation. Siva-1's repressive effect on $I L-2$ gene expression appears to be mediated by inhibition of NFkappaB, whereas FOXP3 repressed both NFkappaB and NFAT activity.

Conclusions: In summary, our data suggest that both FOXP3 and Siva function as negative regulators of IL-2 gene expression in $T_{\text {reg }}$ cells, via suppression of NFAT by FOXP3 and of NFkappaB by both FOXP3 and Siva. Our work contributes evidence for Siva's role as a T cell signalling mediator in addition to its known pro-apoptotic function. Though further investigations are needed, evidence for the biophysical interaction between FOXP3 and Siva invites the possibility that Siva may be important for proper $T_{\text {reg }}$ cell function.
\end{abstract}

\section{Background}

The transcription factor Foxp3 is essential for immune system regulation due to its role in the development and function of regulatory $\mathrm{T}$ cells $\left(\mathrm{T}_{\text {regs }}\right)[1,2]$. The dramatic autoimmune phenotype that is caused by mutated Foxp 3 in both mice and humans led to its initial identification $[2,3]$. In the absence of Foxp3, lethal autoimmunity ensues. Sequencing of the FOXP3 genes from IPEX (Immune polyendocrinopathy, enteropathy, $\underline{X}$-linked) patients revealed function ablating mutations throughout domains critical for FOXP3 function $[4,5]$. The scurfy mouse is an autoimmune mutant that has a spontaneous truncation mutation in Foxp3. In addition to its well-studied role in $\mathrm{T}_{\text {regs }}$, an emerging body of work has revealed Foxp3 to be a tumor suppressor in breast cancer [6,7]. Foxp3 activates and suppresses a broad range of genes, but the mechanisms by which this happens are not well-understood [8-10]. By understanding the relationship between FOXP3

\footnotetext{
* Correspondence: Isu@med.unc.edu

'Lineberger Comprehensive Cancer Center, School of Medicine, The University of North Carolina at Chapel Hill, Chapel Hill, NC 27599, USA Full list of author information is available at the end of the article
}

and its binding partners, we hope to illuminate how FOXP3 operates as a powerful regulator of immune activation.

Already, FOXP3 is reported to reside in a supramolecular complex [11] and a number of specific interactions have been identified [12]. Co-immunoprecipitation (CoIP) demonstrated binding between FOXP3 (or Foxp3) and the following partners: the NF $\kappa \mathrm{B}$ p65 subunit [13], TIP60, HDAC7, HDAC9 [14], FOXP1 [11], Runx1/AML1 [15], the AP-1 constituent, cJUN [16], ROR $\alpha$ [17], ROR $\gamma$ t $[18,19]$, and Eos [20]. Also, Foxp3 homo-oligomerizes $[11,21]$. Wu el al [22] demonstrated that Foxp3 inhibits the transcriptional enhancing effects of NFAT and AP-1 by disrupting their interaction.

Regulation of $I L-2$ gene expression is critical to immune tolerance, $T_{\text {reg }}$ development and $T_{\text {reg }}$ function [23,24]. Foxp3 inhibits $I L-2$ production in $\mathrm{T}_{\text {regs }}$ and confers $I L-2$ suppressive function in trans [25]. Even before $\mathrm{T}_{\text {regs }}$ and Foxp 3 became inextricably coupled, researchers investigated the effect of Foxp3 on $I L-2$ transcription [26]. While $I L-2$ is not the sole target of Foxp3 [9], coordinated investigations into molecular interactions localized to the $I L-2$ 
promoter have been a successful strategy thus far, towards understanding Foxp3's function as a transcriptional regulator.

Here we report a previously unidentified FOXP3 binding partner, Siva. The novel interaction was exposed in a yeast two-hybrid screen for FOXP3 binding partners. We were interested in Siva for its known cell death promoting properties $[27,28]$. The possibility of a pro-apoptotic molecule that might confer $\mathrm{T}_{\text {reg }}$ properties was intriguing. Also, Siva binds tumor necrosis factor receptor (TNFR) family members associated with (but not exclusive to) the $\mathrm{T}_{\text {reg }}$ surface phenotype: CD27, GITR (glucocorticoid-induced TNFRrelated protein), and OX40 [27-33]. Siva was first identified based on its CD27-binding activity, which was demonstrated by Co-immunoprecipitation (Co-IP) studies in 293T cells transiently transfected with CD27 and GFPtagged Siva [27]. In a subsequent study, the same group showed that the CD27 cytoplasmic tail mediated the interaction between both isoforms, Siva-1 and Siva-2 [28]. The cytoplasmic region of CD27 shares a high degree of homology with GITR, and OX40, which prompted the investigation and confirmation that these other TNFR family members also interact with Siva [29]. GITR is highly expressed on $\mathrm{T}_{\text {regs }}$ and attributes suppressive properties under certain conditions [34,35]. In a transient transfection system, Siva and GITR functionally interacted to exacerbate apoptosis [29]. Thus, we investigated Siva because of its pro-apoptotic properties and its ability to bind TNFR family members that are associated with the $\mathrm{T}_{\text {reg }}$ surface phenotype.

Our data shows a physical interaction between FOXP3 and Siva protein exogenously expressed in 293T cells. We mapped the FOXP3-interacting domain to the C-terminus of Siva. The central portion of FOXP3 (amino acids (AAs) 106-332) contains Siva-binding activity. We found that Siva repressed IL-2. The repressive effect of Siva on $I L-2$ appears to be mediated by $\mathrm{NF} \kappa \mathrm{B}$, as our data and others show a negative regulatory effect for Siva on $\mathrm{NF} \kappa \mathrm{B}$ activity [36]. Consistent with previous reports [13,22], we observed that FOXP3 repressed NF $\kappa \mathrm{B}$ and NFAT. To conclude, while the pro-apoptotic effect of Siva has been thoroughly demonstrated and documented, this analysis of Siva's effect on $I L-2$ contributes evidence for Siva's role in T cell signalling.

\section{Results}

\section{Siva physically interacts with FOXP3}

A yeast two-hybrid screen for FOXP3-binding partners was performed with a human thymus cDNA library. Six full-length clones for Siva-1 were identified in the screen. We chose Siva-1 for further investigation for two reasons. First, Siva regulates T cell apoptosis and, second, because Siva associates with TNFR family members that might contribute to $\mathrm{T}_{\text {reg }}$ function: CD27, GITR, and OX40 [29-33].

We tested whether FOXP3 and Siva could interact in mammalian cells. Two isoforms, Siva-1 and Siva-2 [28], have been described and their protein domain organization is depicted in Figure 1A [GenBank: NP_006418, NP_068355]. Siva-2 lacks the second exon, resulting in a protein that is missing most of the spherical amphipathic helix (SAH) and death domain homology region (DDHR) [28]. We performed co-immunoprecipitation (Co-IP) experiments with transfected $293 \mathrm{~T}$ cell lysates. We transfected 293T cells with expression plasmids for EGFPtagged Siva isoforms and Myc-tagged FOXP3, or the appropriate vector control. Myc/FOXP3 was immunoprecipitated with a mouse anti-Myc hybridoma supernatant, 9E10. As shown in Figure 1B, by western blotting (WB) with an antibody against GFP, we detected Co-IP of Siva-1 and Siva-2 in the presence of Myc/FOXP3, but not in its absence. EGFP alone did not Co-IP with FOXP3 (data not shown). Thus both Siva-1 and Siva-2 specifically interact with FOXP3.

Next, we wanted to know whether Siva was expressed in FOXP3-expressing $\mathrm{T}_{\text {reg }}$ cells. We examined Siva expression profiles contained within the microarray dataset generated by Fontenot et al. from Foxp $3^{G F P}$ knock-in mice [33]. Fontenot et al. sorted CD4 ${ }^{\text {pos }} \mathrm{T}$ cells for CD25 and Foxp $3^{\mathrm{GFP}}$. The data shown in Figure $1 \mathrm{C}$ demonstrates that Siva is expressed in CD4 $4^{\text {pos }} \mathrm{T}$ cells that are both positive and negative for Foxp3 expression. Siva is preferentially associated with CD25, a marker associated with both the $\mathrm{T}_{\text {reg }}$ phenotype and $\mathrm{T}$ cell activation. Thus, Siva and Foxp 3 are co-expressed in mouse $\mathrm{T}_{\text {regs }}$ that express the CD25 surface marker.

\section{Siva-binding activity is contained within FOXP3's central region}

Major domains of the FOXP3 protein are associated with specific functional activities and binding partners (Figure 2A) [GenBank: NP_054728, NP_001107849] [12]. The Foxp3 N-terminus is required for NFATmediated repression of $I L-2$ [22] and is involved in binding to the ROR $\gamma \mathrm{t}$ and $\mathrm{ROR} \alpha$ transcription factors [19]. The leucine zipper (L zip) domain mediates homodimerization of Foxp3, which contributes to $\mathrm{T}_{\text {reg }}$ suppressive function [11,21]. The C-terminal Foxp3 forkhead (Fkh) domain is required for DNA binding and nuclear localization [26]. A short stretch of amino acids between the zinc finger ( $\mathrm{Zn} \mathrm{F}$ ) and the Fkh domain is involved in Runx1/AML1 binding and is involved in $I L-2$ repression [15].

We used Myc/FOXP3 truncation mutants to characterize the region involved in binding to Siva by Co-IP in $293 \mathrm{~T}$ cells (summarized in Figure 2A). Mutants lacking 


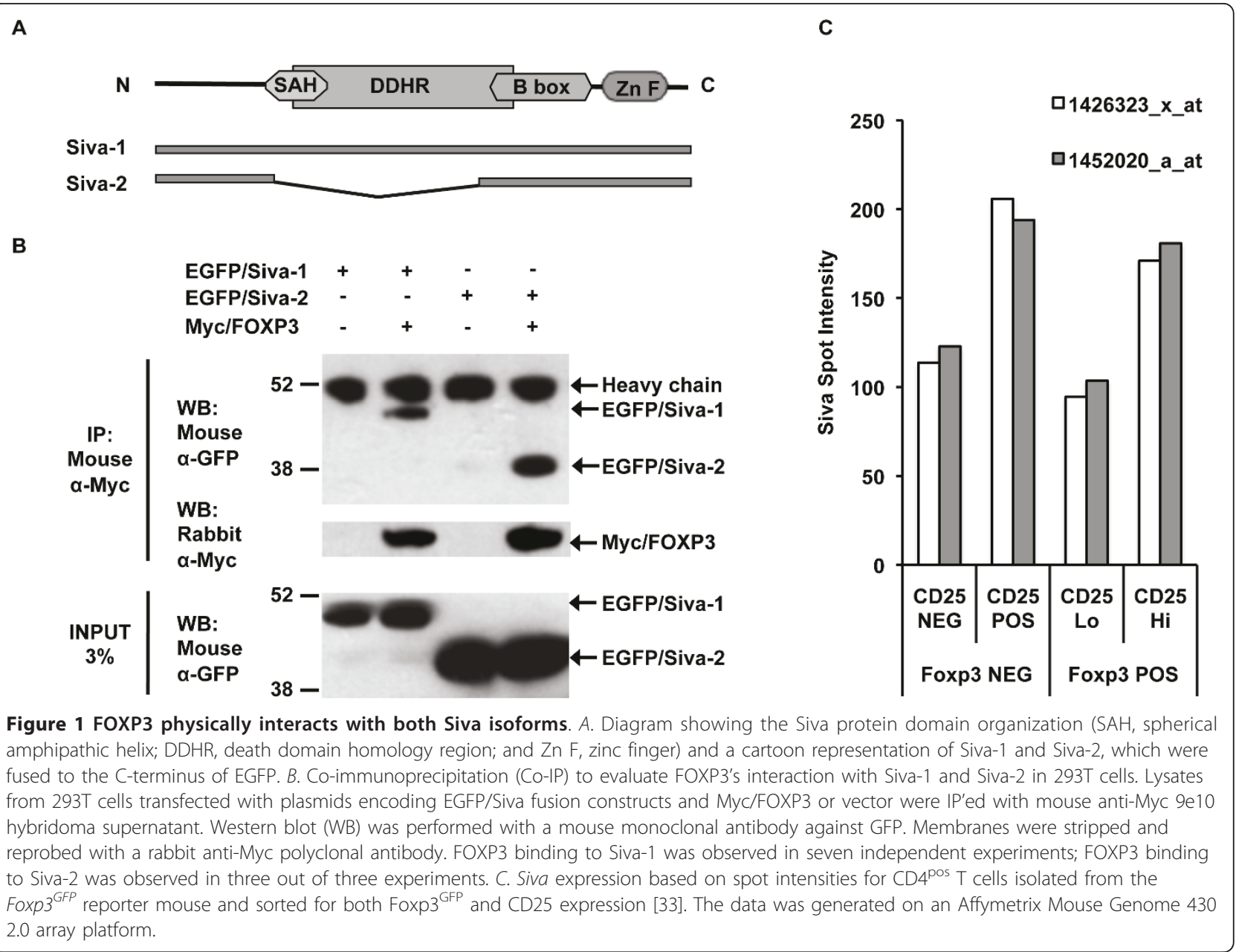

the Fkh domain $(\Delta \mathrm{Fkh})$ or the $\mathrm{N}$-terminus $(\Delta 1-71 ; \Delta 1$ $105)$ bound to Siva with similar efficiency as full length FOXP3 (Figure 2B). The FOXP3 Fkh mutant repeatedly showed lower expression than other FOXP3 mutants (Figure 2B and not shown). The reduced level of expression might have contributed to the lack of binding between FOXP3 Fkh and EGFP/Siva-1. Still, based on the Siva-binding activity of the $\Delta \mathrm{Fkh}$ mutant, we conclude that the FOXP3 Fkh domain is not necessary for Siva-binding activity. FOXP3's Siva-binding activity is located within the protein's central region (AAs 106332), which spans the leucine zipper, the zinc finger and Runx1-binding domains.

\section{The Siva C-terminus is sufficient to bind FOXP3}

As shown in Figure 3A, we designed Siva truncation mutants fused to EGFP's C-terminus to cover major domains that have been previously described and associated with functional properties $[27,28,37]$. We performed Co-IPs to map Siva's FOXP3-binding activity. Our analysis definitively showed no interaction between
FOXP3 and Siva mutants lacking the C-terminus (Figure $3 \mathrm{~B})$. In contrast, all mutants containing some portion of the cysteine rich Siva C-terminal domain interacted with FOXP3. Given that the Siva C-terminus mutant and the $\triangle \mathrm{Zn} F$ mutant both contain the B box domain and both interacted with FOXP3, we hypothesized that the Siva B box domain might be necessary and sufficient to bind FOXP3. To test our hypothesis, we designed mutants encompassing the Siva B box domain and full length Siva lacking the B box domain ( $\triangle \mathrm{B}$ box). Subsequent Co-IP experiments demonstrated a very weak, but detectable interaction between FOXP3 and the Siva B box domain. The Siva $\Delta B$ box mutant was fully competent to bind FOXP3. Thus, the Siva B box domain appears unnecessary and insufficient to bind FOXP3 (Figure 3C).

\section{Siva negatively regulates $I L-2$ gene expression}

We next investigated Siva's effect on IL-2 gene expression. In order to evaluate the effect of Siva overexpression on endogenous IL-2, we transduced Jurkat $\mathrm{T}$ cells with pHSP-EGFP/Siva-1 or pHSPG-Siva-1 retrovirus 
A FOXP3 protein organization \& FOXP3 truncation mutants

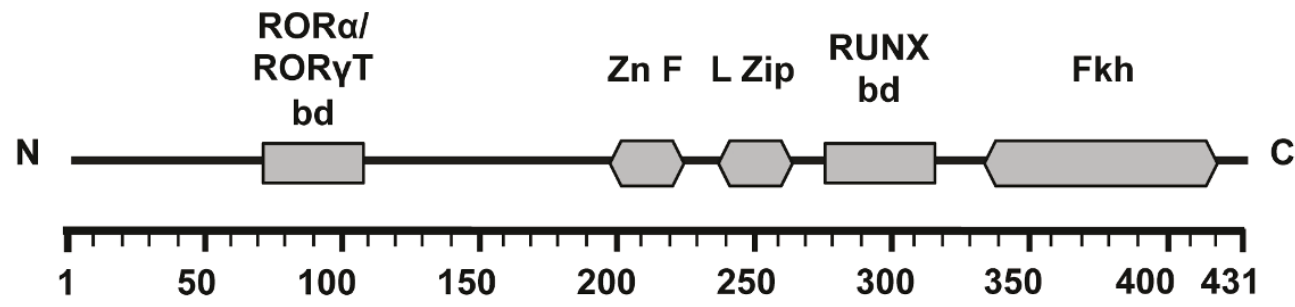

Binds to

$150-100-150-200-250 \div 300 \div 350$

Siva-1?

FL

Fkh

$\Delta$ Fkh

$\Delta 1-71$

$\Delta 1-105$

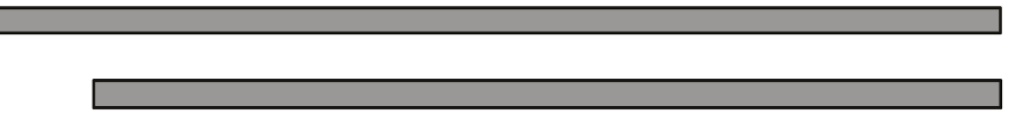

B

$$
\text { Inputs (5\%) IP with Mouse } \alpha-M y c
$$

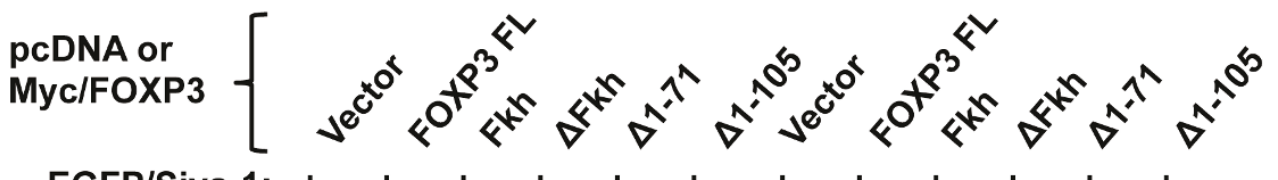

EGFP/Siva-1: ++++++++++++

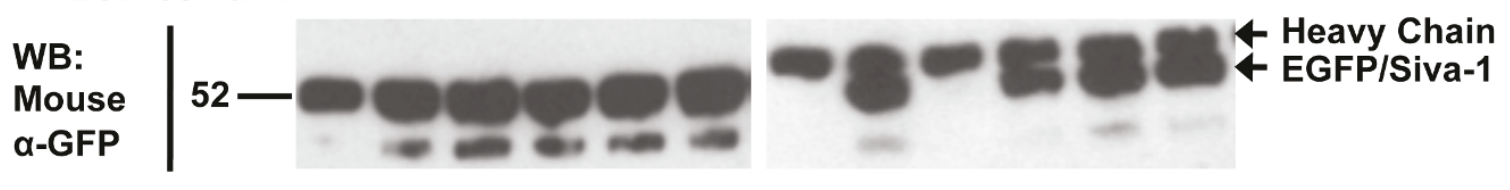

Mouse

\begin{tabular}{l|l} 
& $52-$ \\
\begin{tabular}{l|} 
WB: \\
Rabbit \\
a-Myc
\end{tabular} & $38-$ \\
& $31-$
\end{tabular}
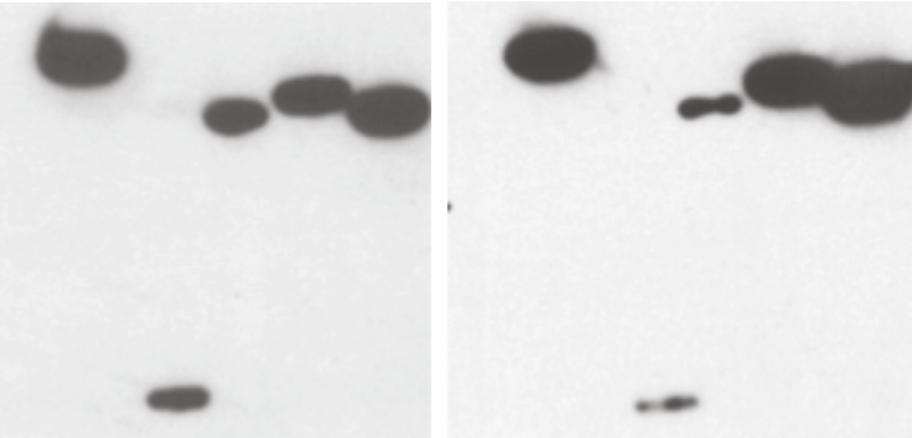

4 Myc/FOXP3 FL

$\leftarrow$ Myc/FOXP3 $\Delta 1-71$

- Myc/FOXP3

$\Delta 1-105$ and $\Delta \mathrm{Fkh}$

Figure 2 Siva-binding activity is contained within a central portion of the FOXP3 protein (amino acids 106-332). A. Diagram depicting FOXP3 protein domain organization and truncation mutants that were fused to the Myc C-terminus and used in the Co-IP shown in B. (bd, binding domain; Zn F, zinc finger; L Zip, leucine zipper; Fkh, forkhead). B. Co-immunoprecipitation (Co-IP) to map FOXP3's Siva-binding activity. Co-IPs were performed as described in Figure 1. Binding between the FOXP3 Fkh mutant and Siva was tested three times. The other FOXP3 mutants shown here were tested once. 
A Siva protein organization \& Siva truncation mutants

N

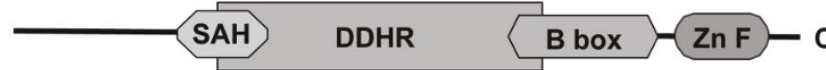

Siva-1

Siva-2

$\mathbf{N}$

$\Delta C$

DDHR

$\Delta \mathrm{Zn} F$

$\Delta \mathbf{N}$

C

B box

$\Delta \mathrm{B}$ box
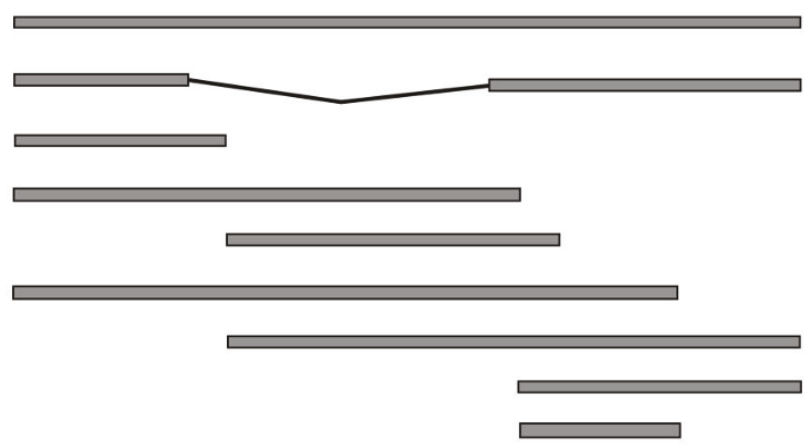

Binds to FOXP3?

$+$

$+$

(-)

(-)

(-)

$+$

$+$

$+$

(-)

B

Siva Mutant IP

IP with Mouse $\alpha-M y c$

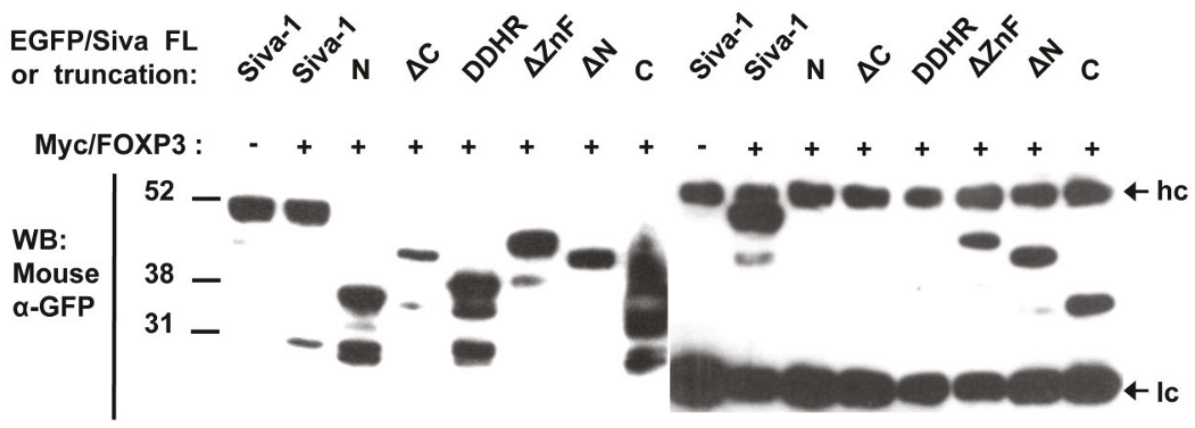

C

Siva B box Mutant IP

Inputs (3\%)

IPs (Mouse anti-Myc)

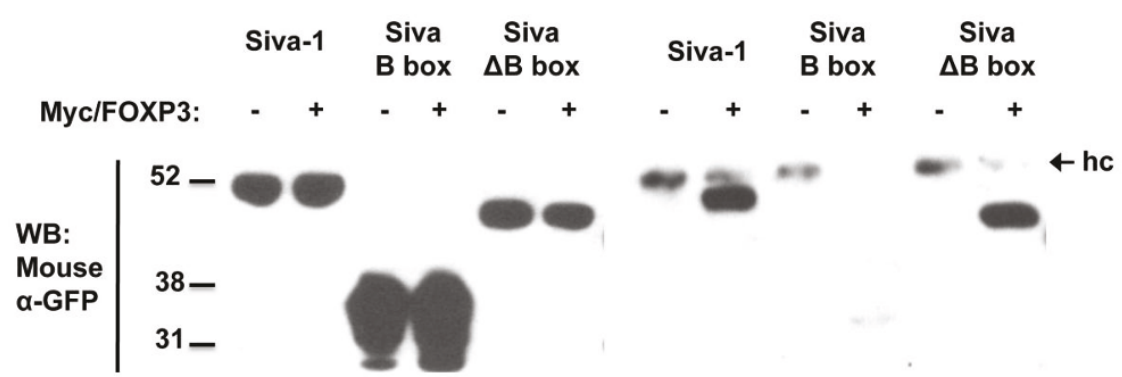

Figure 3 The Siva C-terminus is sufficient to bind FOXP3. A. Diagram showing the Siva protein domain organization (SAH, spherical amphipathic helix; DDHR, death domain homology region; B box; and Zn F, zinc finger) and Siva truncation mutants, which were fused to the EGFP C-terminus and tested in Co-IPs shown in B and C. B. Co-IP to map Siva's FOXP3-binding activity (hc, antibody heavy chain; Ic, antibody light chain). These Siva truncation mutants were tested three times for FOXP3-binding activity. C. Co-IP to test the FOXP3-binding activity of the Siva $B$ box and $\triangle B$ box mutants. These mutants were each tested twice for FOXP3-binding activity. 
(RV). Figure 4A shows a representative gating scheme used to measure cell viability and transduction efficiency. This basic gating scheme was used in subsequent experiments throughout this report. For each experiment, $\mathrm{GFP}^{\text {neg }}$ cells were used to determine the position of all gates and quadrant boundaries. We normalized IL-2 expression levels to viable cell counts in order to examine Siva's effect on IL-2 separate from Siva's effect on apoptosis. The repressive effect of EGFP/Siva-1 and Siva-1 on endogenous IL-2 in Jurkat T cells are shown in Figures $4 \mathrm{~B} \& 4 \mathrm{C}$, respectively. EGFP/Siva-1 repressed endogenous IL-2 by nearly $90 \%$ compared to pHSPG transduced cells (Figure 4B). In a separate experiment, overexpression of Siva-1 also repressed endogenous IL-2 gene expression (Figure 4C). Next, we tested the effect of Siva knockdown (KD) on endogenous IL-2 gene expression (Figure 4D). Jurkat $\mathrm{T}$ cells were transduced with pLKO lentivirus (LV) expressing shSiva or shEGFP, as a control shRNA. The DNA gel confirms Siva KD based on RT-PCR using primers specific for both Siva isoforms. Siva KD enhanced IL-2 gene expression compared to the shEGFP control, providing further evidence that Siva acts as a negative regulator of $I L-2$ gene expression.

\section{Siva negatively regulates IL-2 promoter activity}

In addition to measuring Siva's effect on endogenous IL-2 protein levels, we tested the effect of Siva gene expression on $I L-2$ promoter activity. A minimal enhancer element located 300 base pairs immediately upstream of the $I L-2$ start site regulates transcription through the binding of transcription factors and alterations in the chromatin structure $[38,39]$. Distal regulatory elements also contribute to $I L-2$ gene regulation and the minimal enhancer region is sometimes referred to as the proximal promoter. In order to investigate Siva's effect on $I L-2$ transcriptional activation, we used a reporter plasmid containing the $I L-2$ proximal promoter driving expression of the luciferase enzyme. Again, in order to examine Siva's effect on IL-2 separate from Siva's effect on apoptosis, we normalized IL2 transcriptional activity to viable cell counts. Siva overexpression inhibited $I L-2$ transcriptional activity (Figure 5A) and Siva KD enhanced $I L-2$ transcription (Figure 5B).

\section{FOXP3 and Siva repress endogenous IL-2 gene expression} In order to test whether FOXP3 and Siva functionally interact to repress endogenous IL-2, we co-expressed FOXP3 and Siva-1 in Jurkat cells by transduction with

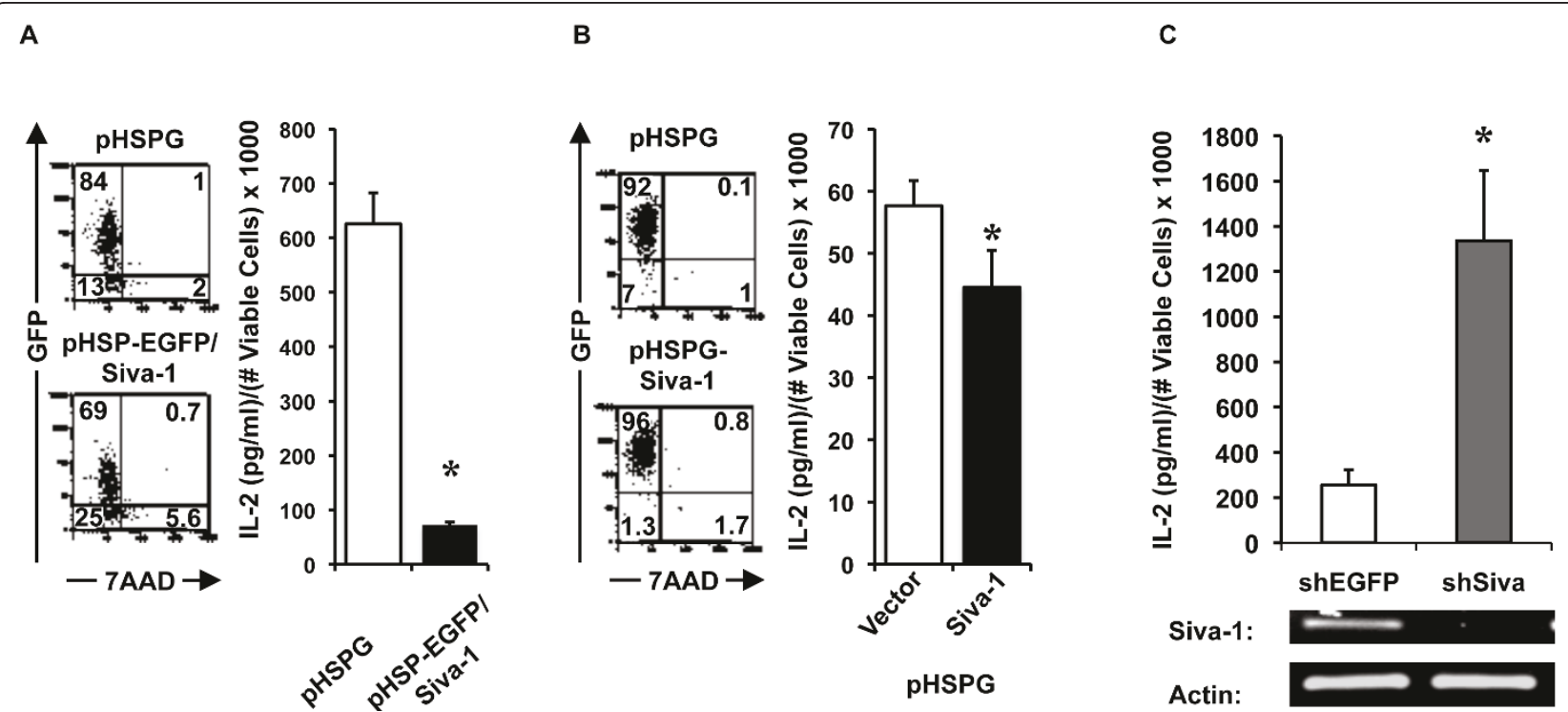

Figure 4 Siva represses endogenous IL-2 gene expression. A. The flow plot gating scheme used in B and C is shown. An FSC high gate was drawn to include 7AAD ${ }^{\text {pos }}$ cells, but exclude debris events that would falsely appear as viable, 7AAD ${ }^{\text {neg }}$ cells in subsequent analyses. 7AAD ${ }^{\text {neg }}$ events included in the FSC high gate were used to calculate viable cell number. GFP is being detected in the YFP channel, which was not used in any of these experiments. In B-D, IL-2 expression levels were divided by the mean viable cell number for each indicated sample. B. Flow plots indicating viability and transduction efficiency based on GFP expression for Jurkat T cells transduced with pHSPG retrovirus (RV) or RV expressing an EGFP/Siva-1 fusion protein (pHSP-EGFP/Siva-1). Transduced Jurkat T cells were subsequently tested for IL-2 production in response to PMA and lonomycin. C. Similarly to data shown in B, the flow plots show Jurkat T cells transduced with RV from pHSPG or pHSPG encoding untagged Siva-1. IL-2 protein expression in response to PMA and lonomycin for the same cells is shown. D. Knockdown (KD) of endogenous Siva with shRNA enhanced endogenous IL-2 expression. Siva-1 KD efficiency was evaluated by standard RT-PCR and DNA bands are shown. In B-D, error bars represent standard deviations for $n=3$; * indicates $p<0.05$ for two-tailed Student's t-test between vector transduced cells and the respective EGFP/Siva-1, Siva-1 or shSIVA expressing cells. Data shown in B-D is from one experiment representative of 3-5 replicates. 
A

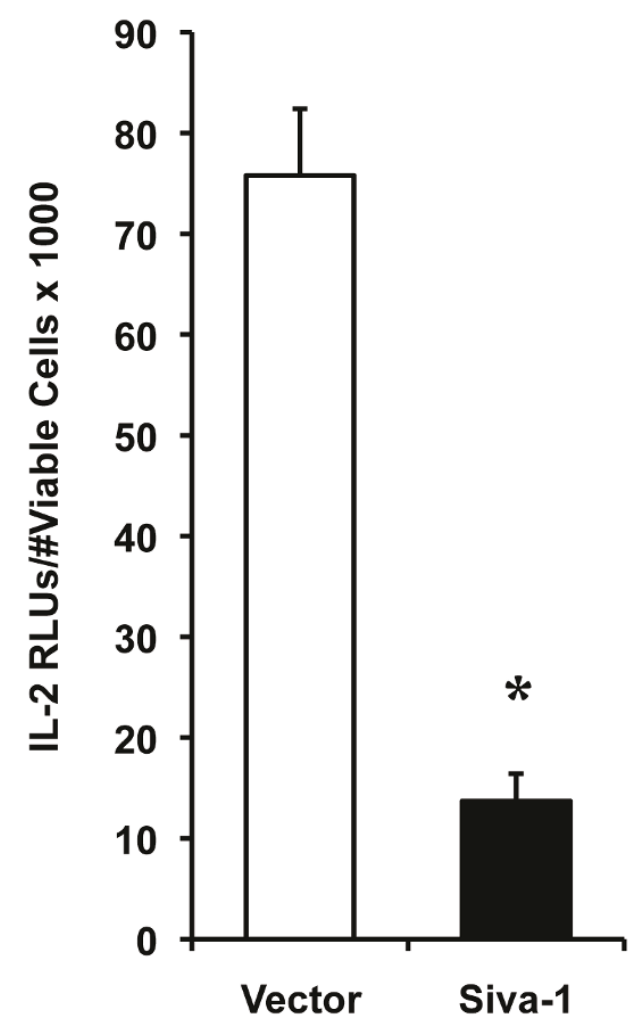

B

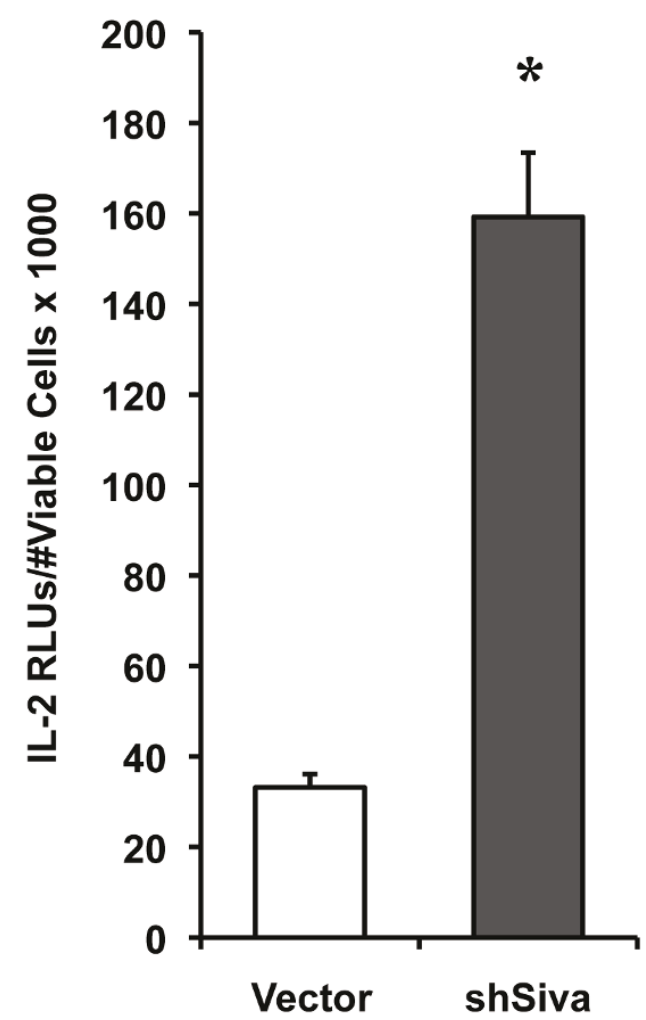

Figure $\mathbf{5}$ Siva represses $\mathbf{I} \mathbf{L}-\mathbf{2}$ promoter activity. To evaluate $\mathbf{L}-2$ promoter activity, Jurkat $T$ cells were transfected with an $\mathbf{L}-2$ luciferase reporter plasmid plus other constructs to overexpress or KD Siva expression. $/ L-2$ promoter-driven luciferase activity is expressed as a measure of relative light units (RLUs) normalized to the viable cell number. $A$. Siva-1 overexpression with pHSPG-Siva-1 repressed $1 L-2-$ promoter activity. $B$. Siva KD by shRNA had an enhancing effect on $I L-2$ promoter activity. ${ }^{*}$ s indicate statistical difference compared to vector based on $\mathrm{p}<0.05$ by a two-tailed Student's t-test. These experiments were each performed twice and a result from one representative experiment is shown.

pHSPG RV (Figure 6A). As expected, FOXP3 and Siva-1 each repressed endogenous IL-2 independently (Figure $6 \mathrm{~B})$. The combination of FOXP3 and Siva-1 failed to repress IL-2 further than FOXP3 alone. We also examined the combined effects of Siva KD and exogenous FOXP3 on IL-2. Figure 6C shows the efficiency of Siva KD in Jurkat T cells transduced with pLKO LVs expressing hairpin RNA against Siva or EGFP and PG RV expressing FOXP3. Consistent with data shown above, Siva KD enhanced IL-2 gene expression (Figure 6D). FOXP3 effectively repressed IL-2 gene expression independent of endogenous Siva expression levels. Thus, in this experimental system, FOXP3-mediated repression of endogenous IL-2 appears to be independent of Siva gene expression levels.

\section{Effect of FOXP3 and Siva on IL-2 promoter activity}

In addition to evaluating the combined effects of FOXP3 and Siva on endogenous IL-2 gene expression, we investigated whether the two genes might functionally interact to repress $I L-2$ transcriptional activity. First, we tested the effect of FOXP3 and Siva-1 overexpression on the transcriptional activity of the $I L-2$ proximal promoter in the Jurkat $\mathrm{T}$ cell luciferase assay. We transfected Jurkat T cells with the $I L-2$ reporter plasmid and different combinations of pHSPG, pHSPG-Siva-1 and pHSPG-FOXP3 in equal plasmid DNA mass. As indicated by the data in Figure 7A, both Siva-1 and FOXP3 repress $I L-2$ transcriptional activity independently. The repressive effect of FOXP3 is stronger than Siva-1. We do not see an additive effect on $I L-2$ repression between Siva-1 and FOXP3. In addition, we tested the combined effect of Siva KD and FOXP3 overexpression on $I L-2$ transcriptional activity (Figure 7B). As expected, Siva $\mathrm{KD}$ enhanced $I L-2$ transcriptional activity. However, FOXP3 over expression masked the IL-2 enhancing effect of Siva KD. Thus, similar to the endogenous IL-2 experimental results, the IL-2 transcriptional activity assays suggest that FOXP3's repressive effect masks the repressive effect of Siva. 
A

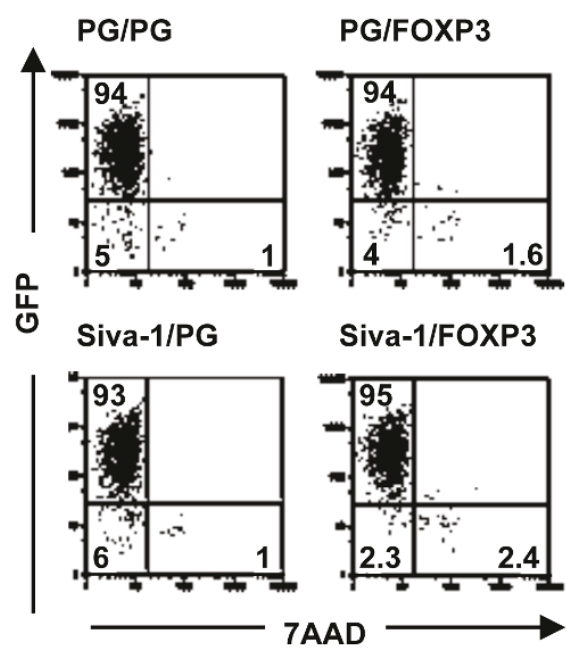

C

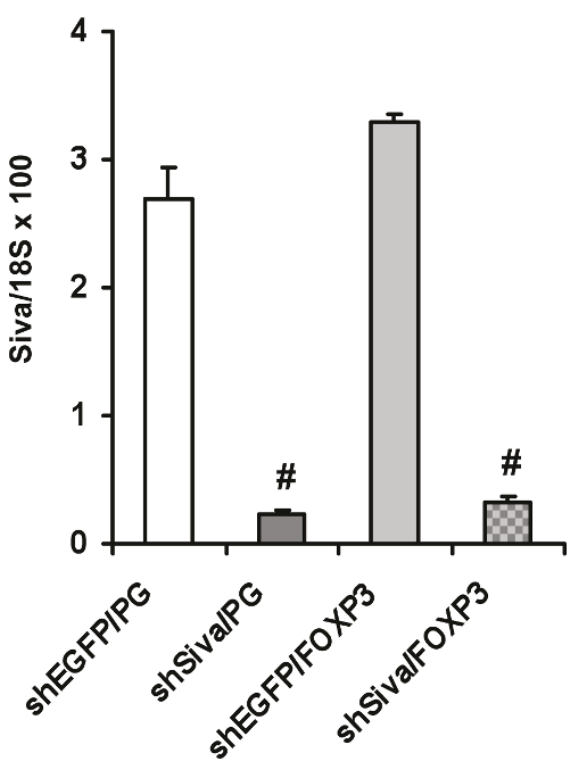

B

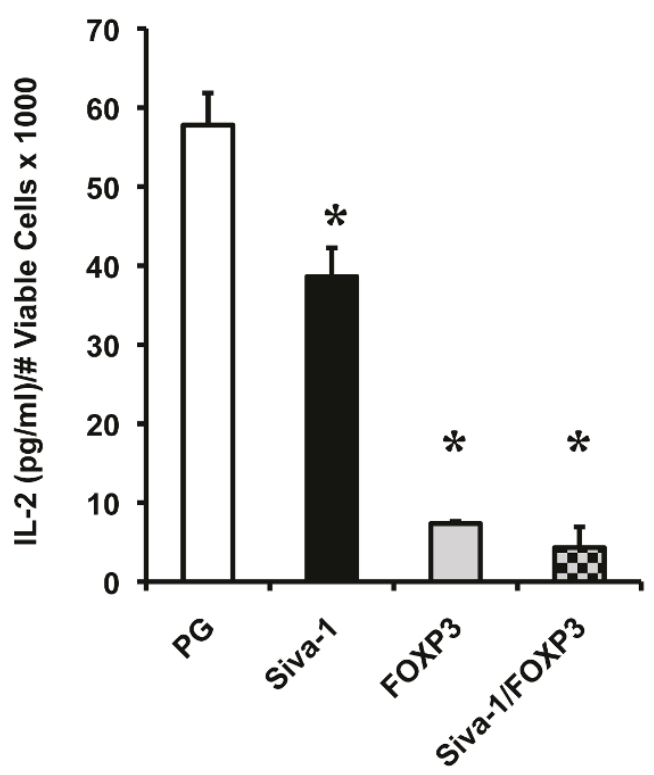

D

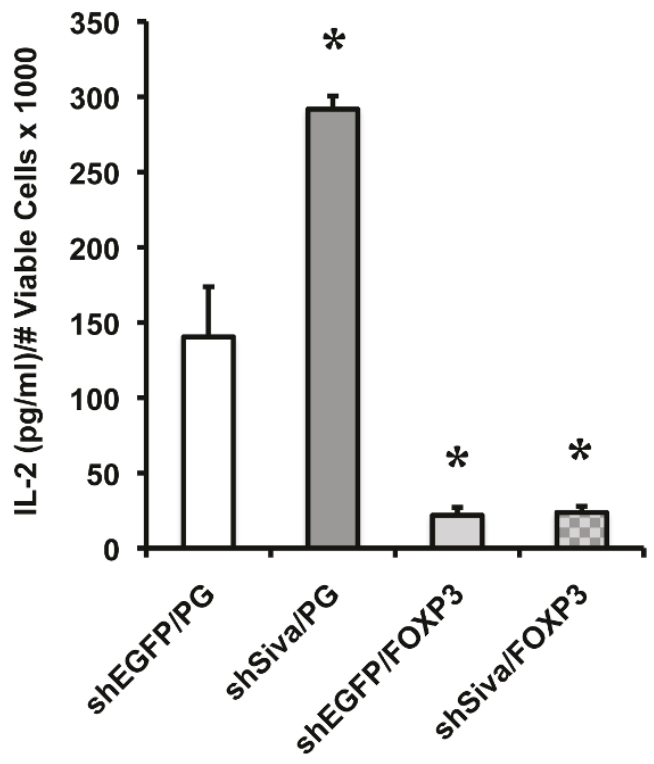

Figure 6 Endogenous IL-2 in response to exogenous FOXP3 combined with Siva-1 overexpression or Siva knockdown. Jurkat T cells were transduced with two rounds of RV or LV and then activated with PMA and lonomycin. Following stimulation, cell viability was determined using the gating method shown in Figure 4A and endogenous IL-2 expression was measured by ELISA. A. Flow cytometry for GFP expression and viability in unstimulated Jurkat T cells transduced with different combinations of pHSPG (PG), PG-Siva-1, and PG-FOXP3 RV. Plots shown have already been gated to exclude debris events using a gating scheme similar to the one shown in 4A. B. Endogenous IL-2 in response to FOXP3 and Siva-1 overexpression was determined using the cells shown in A. The IL-2 concentration was divided by the mean viable cell count for each indicated sample. C. Siva KD efficiency was determined by quantitative realtime PCR for Siva and 185 in unstimulated Jurkat T cells transduced with PG or PG-FOXP3 RV and pLKO-shEGFP or PLKO-shSIVA LV. The realtime PCR primers used in this experiment do not distinguish between the two Siva isoforms. The error bars indicate standard deviation between technical replicates. \#s indicate statistically significant difference between the indicated bar and the adjacent, shEGFP-transduced control. D. Endogenous IL-2 in response to FOXP3 overexpression and Siva KD, using the transduced Jurkat T cells described in C. *s indicate statistically significant difference between the indicated bar and the PG- or shEGFP/PG-transduced control, in B and D, respectively. Statistically significant difference was based on $p<0.05$ by a two-tailed Student's t-test. These transduction experiments were performed twice and representative experiments are shown. 


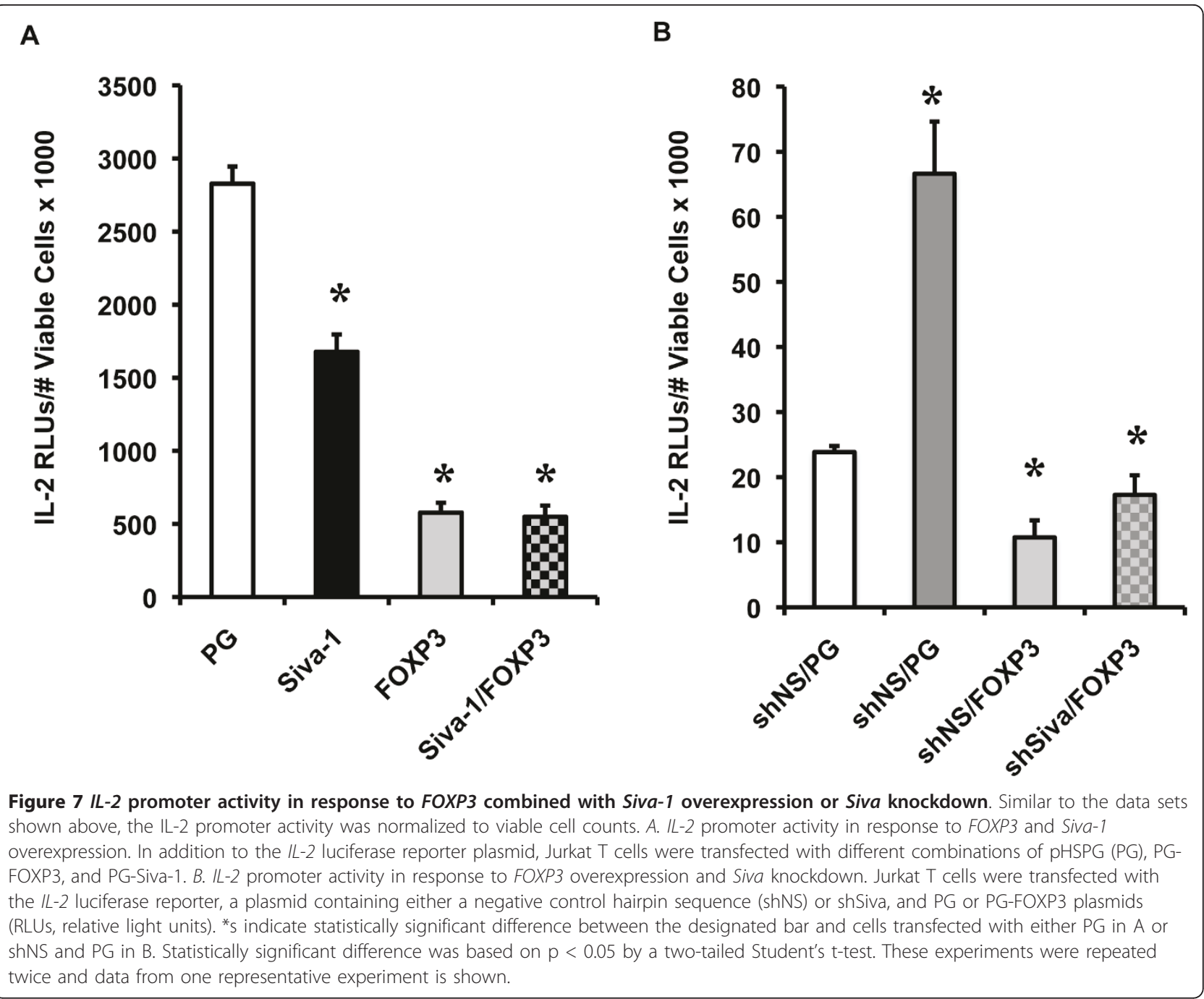

Effects of FOXP3 and Siva-1 on NF $\kappa$ B and NFAT activity $I L-2$ is regulated by multiple transcription factors and chromatin modifications $[38,39]$. We tested the effects of Siva-1 and FOXP3 on the transactivating potential of two major $I L-2$ transcriptional regulators, $N F \kappa \mathrm{B}$ and NFAT. In these experiments, the reporter construct contains a luciferase gene that is regulated by three tandem repeats of either the NF $\kappa \mathrm{B}$ consensus sequence from the MHC class I promoter [40] or the NFAT binding site from the human IL-2 gene promoter [41]. Consistent with published reports and shown in Figure 8, FOXP3 inhibits NF $\kappa \mathrm{B}[13]$ and NFAT [13,22] transactivation potential in Jurkat T cells. Siva repressed $\mathrm{NF} \kappa \mathrm{B}$ (Figure 8A), but had no effect on NFAT activity (Figure $8 \mathrm{~B})$. The combination of FOXP3 and Siva-1 repressed $\mathrm{NF} \kappa \mathrm{B}$ activity more than FOXP3 alone. Even though the $\mathrm{NF} \kappa \mathrm{B}$ repressive effect of the two genes in combination was slight $(\sim 20 \%)$, the effect was reproducible with statistical significance.

\section{Discussion}

In this report we have shown that FOXP3 and Siva physically interact. We have mapped the binding activities to limited domains within each protein. FOXP3 and Siva-1 both independently repressed $I L-2$ gene expression. One mechanism by which Siva-1 represses $I L-2$ is via inhibition of $\mathrm{NF} \kappa \mathrm{B}$. In contrast, FOXP3 repressed the activity of both $I L-2$ transactivators tested here, $\mathrm{NF} \kappa \mathrm{B}$ and NFAT. Although we did not reveal a functional interaction between FOXP3 and Siva with regards to IL-2 repression, the biophysical interaction invites questions regarding how Siva might contribute to regulation of FOXP3-expressing $\mathrm{T}_{\text {reg }}$ cells.

The physical interaction was demonstrated through a standard protein-protein interaction, Co-IP assay. Two Siva isoforms have been identified and both Siva isoforms interact with FOXP3. The Siva-2 isoform lacks the second exon that encodes for the SAH and DDHR domains $[28,37]$, which were found to be dispensable for binding 
A

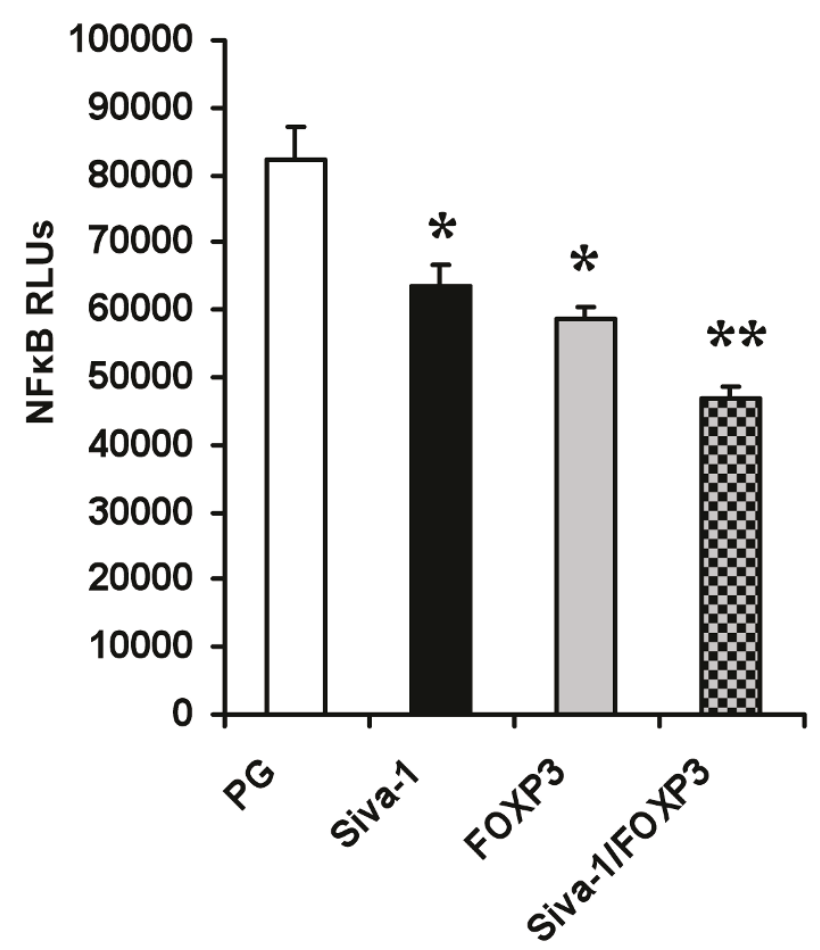

B

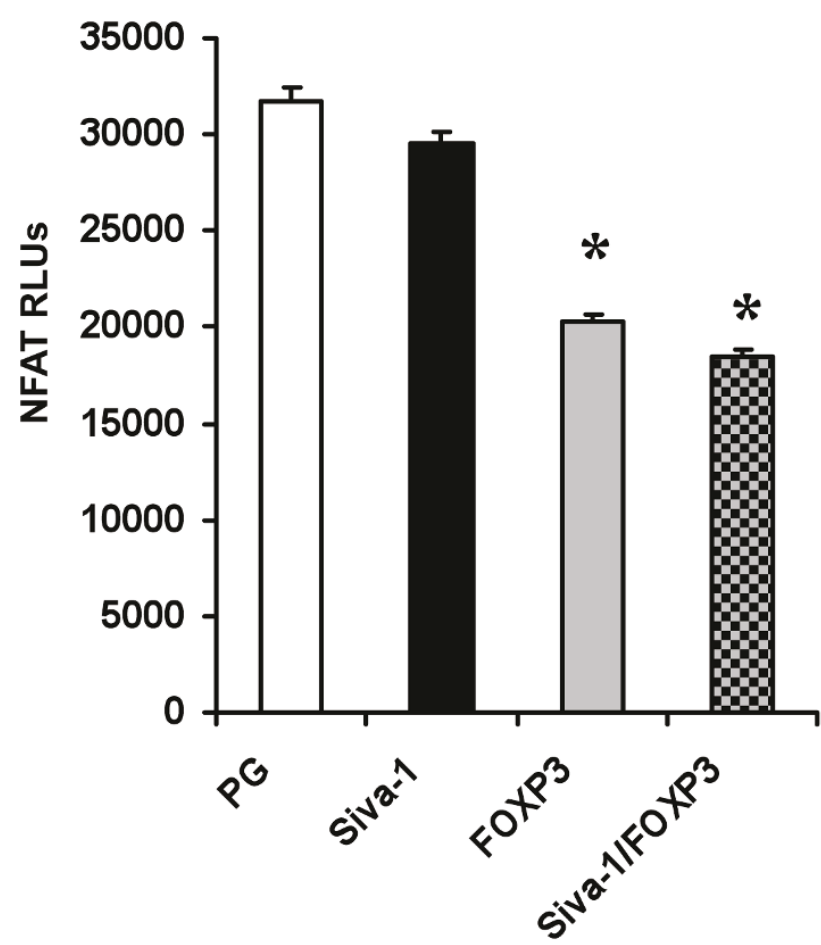

Figure $8 \mathrm{NF} \kappa \mathrm{B}$ and NFAT reporter activity in response to Siva-1 and FOXP3 overexpression. Jurkat T cells were transfected with NF $\kappa B$ and NFAT luciferase reporter plasmids and expression plasmids encoding FOXP3 or Siva-1 or the parental vector control, pHSPG (PG) (RLUs, relative light units). A. Both FOXP3 and Siva-1 repress NF $\kappa$ B activity in response to PMA and lonomycin. B. FOXP3 repressed NFAT activity in response to PMA and lonomycin. *s indicate statistically significant difference between the indicated bar and the PG vector control based on $p<0.05$ by a two-tailed Student's t-test. ** indicates statistically significant difference between Siva-1 and FOXP3 in combination compared to FOXP3 alone. These experiments were repeated twice and data from one representative experiment is shown.

FOXP3 in subsequent Siva truncation Co-IP experiments. The Siva C-terminus, which encompasses both the putative B box and Zn F domains, contained FOXP3 binding activity.

The Siva C-terminus is enriched with cysteine residues that could be important to the protein's tertiary structure and function. Paired cysteine residues are associated with intramolecular disulfide bond formation. The Siva C-terminus contains six paired cysteine residues. Nestler et al [42] used truncation mutants to show that Siva coordinates three zinc ions, two of which are associated with the C-terminus [42]. Although a few groups have found that the Siva C-terminus is necessary to interact with other binding partners [43-45], no one has described whether specific C-terminal point mutations block Siva function. Future site-directed mutagenesis studies of the Siva Cterminal cysteine residues could be informative to further characterize the physical interaction between Siva and FOXP3.

FOXP3's Siva-binding activity is contained within a broad central region that includes the zinc finger, the leucine zipper and the RUNX1 binding domain (amino acids 106-332). Mutants missing either the first $105 \mathrm{~N}$ terminal amino acids or the C-terminal forkhead domain sustained binding to Siva-1. Further experiments are needed to define a minimal region of FOXP3 involved in binding to Siva-1. The FOXP3 leucine zipper domain is required for homodimerization, $I L-2$ repression, and $\mathrm{T}_{\text {reg }}$ suppressive function $[11,21,46]$. Given that the leucine zipper domain is within the region that binds Siva-1, one question we are interested in addressing in the future is whether known leucine zipper IPEX mutations $(\Delta 250$, $\Delta 251)[11,21]$ interfere with FOXP3 binding to Siva-1.

One limitation of this study was that technical challenges obstructed our efforts to detect a biophysical interaction between endogenously expressed FOXP3 and Siva. Also, we have not yet performed sufficient experiments to address whether the biophysical interaction could be linked to any functional interaction. In order to test whether the biochemical interaction between FOXP3 and Siva-1 affects their functional interaction, a minimal region of biochemical interaction for at least one protein 
needs to be identified. More extensive point mutant CoIP experiments for at least one of the proteins could be informative towards defining the relationship between the biophysical interaction and any proposed functional interaction for FOXP3 and Siva-1.

Our initial hypothesis was that FOXP3 and Siva-1 might functionally interact to repress $I L$-2 gene expression. We did not observe an additive repressive effect between FOXP3 and Siva-1 on $I L-2$ gene expression. Instead, our data suggests that FOXP3 might be a dominant suppressor that masks the repressive effects made by Siva-1 on IL-2 gene expression.

Our analysis of two $I L-2$ transactivators supports the assertion that Siva-1 and FOXP3 affect shared and different $I L-2$ regulatory mechanisms. Consistent with previous reports, FOXP3 repressed $\mathrm{NF} \kappa \mathrm{B}$ [22] and NFAT $[13,22]$ transactivation reporters. Siva-1 inhibited $N F \kappa B$, but had no effect on NFAT in cells stimulated with PMA and Ionomycin. We observed a small, but significant additive repressive effect between FOXP3 and Siva-1 on $\mathrm{NF} \kappa \mathrm{B}$ activity.

The NF $\kappa \mathrm{B}$-repressive effects that we observed for FOXP3 and Siva-1 are consistent with published reports. The effects of each gene on NF $\kappa \mathrm{B}$ activity may be partitioned into distinct cytoplasmic and nuclear signalling events. In resting cells, cytoplasmic $\mathrm{I} \kappa \mathrm{B} \alpha$ sequesters the canonical $\mathrm{NF} \kappa \mathrm{B}$ subunits p65 and p50, preventing their nuclear translocation. In response to stimulus, $\mathrm{I} \kappa \mathrm{B} \alpha$ breaks down and releases the NF $\kappa \mathrm{B}$ subunits, which translocate to the nucleus [47]. Siva blocked NF $\kappa$ B nuclear accumulation via stabilization of cytoplasmic $\mathrm{I} \kappa \mathrm{B} \alpha$ [36]. On the other hand, FOXP3 blocked $\mathrm{NF} \kappa \mathrm{B}$ transactivation potential by mechanisms independent of nuclear translocation and DNA binding [13]. Further, our group showed that FOXP3's promoter-dependent effects on $\mathrm{NF} \kappa \mathrm{B}$ transactivating potential were independent of nuclear translocation. FOXP3 enhanced HIV-1 gene expression by increasing the amount of $\mathrm{NF} \kappa \mathrm{B}$ p 65 subunit bound to the LTR (long terminal repeat) [10]. To summarize, in separate experimental systems, inhibition of NF $\kappa$ B activity by Siva has been shown to occur upstream of $\mathrm{I} \kappa \mathrm{B} \alpha$ degradation and nuclear translocation, whereas FOXP3 inhibits $\mathrm{NF} \kappa \mathrm{B}$ activity downstream of $\mathrm{I} \kappa \mathrm{B} \alpha$ degradation. The biophysical interaction that we have presented suggests that another regulatory mechanism could be occurring that would involve co-localization of FOXP3 and Siva-1 within the same subcellular compartment.

Given that Siva has displayed both nuclear and cytoplasmic subcellular localization [43,48-51], the possibility remains that Siva could regulate gene transcription from within the nucleus in addition to its cytoplasmic effect on $\mathrm{NF} \kappa \mathrm{B}$. As of yet, published reports of a nuclear specific function for Siva are lacking. Most detailed investigations of Siva function have examined Siva in relation to transmembrane signalling molecules or mitochondrial-associated apoptosis regulators thought to be present in the cytoplasm, not in the nucleus $[28,29,37,43,44,50,52-54]$. In future studies, it will be interesting to look into whether Siva displays nucleus-specific activities such as direct binding to DNA or chromatin.

\section{Conclusions}

To conclude, we have carried out an analysis of $I L-2$ gene regulation by FOXP3 and Siva in Jurkat T cell lines. FOXP3 and Siva both repress $I L-2$ gene expression independently, though the repressive effect of FOXP3 appears to be dominant over Siva in both assays used here. We have shown that FOXP3 and Siva appear to have a slight, but significant, additive repressive effect on $\mathrm{NF} \kappa \mathrm{B}$ activity. Many questions remain, most importantly, those regarding Siva's contribution to $\mathrm{T}_{\text {reg }}$ development and function. Additional efforts are needed to address these intriguing possibilities.

\section{Methods}

\section{Cell culture and plasmids}

$293 \mathrm{~T}$ cells were grown in DMEM-10\% FetalPlex (Gemini). Jurkat cells were grown in RPMI 1640-10\% fetal bovine serum supplemented with $2 \mathrm{mM}$ L-glutamine, $100 \mathrm{U} / \mathrm{ml}$ penicillin, and $100 \mathrm{mg} / \mathrm{ml}$ streptomycin. When needed, Jurkat cells were selected in $1 \mu \mathrm{g} / \mathrm{ml}$ puromycin (puro). Puro selection took 3-10 days, depending on the transduction efficiency. Puro selection was judged to be complete once cellular debris events measured by Gauva EasyCyte reached less than 10\%. Unless otherwise stated, all tissue culture reagents were purchased from Invitrogen.

Myc/FOXP3 full length and all derivative truncation mutants were expressed in pCDNA3.1 and made as previously described [10].

The human Siva-1 cDNA clone [corresponding to GenBank: NM_006427] was purchased from ATCC (ATCC\#: MGC-17039). By PCR subcloning, we transferred Siva-1 from pCMV-SPORT6 into pEGFP-C1 to generate an enhanced green fluorescent protein (EGFP)/Siva-1 fusion construct. All Siva truncation mutants were derived from pEGFP/Siva-1 by PCR subcloning. The splice overlap extension method was used to generate the Siva-2 [GenBank: NM_021709] and $\Delta B$ box mutants [55]. Siva-1 was subcloned into the pHSPG retroviral vector under control of the MSCV promoter [56]. pHSP-EGFP/Siva was generated by replacing the EGFP cassette with EGFP/Siva under control of the PGK promoter.

A panel of five pLKO lentiviral (LV) vectors expressing short hairpin targets against Siva was purchased and tested for knockdown (KD) efficiency (Open Biosystems). All shSIVA KD experiments in this report used Open 
Biosystems clone TRCN0000118302. pLKO contains a puro selection cassette and the U6 promoter controls hairpin expression. pLKO-shEGFP and pLL5.0-NS served as a negative controls in designated experiments. Dr. James Bear's lab provided the pLL5.0-NS construct [57]. The IL-2 and NFAT luciferase reporters were originally acquired from Dr. Gerald Crabtree's lab [41]. Dr. Albert Baldwin provided us with the $\mathrm{NF} \kappa \mathrm{B}$ luciferase reporter, a construct that was originally designed by Dr. Bill Sugden's group $[40,58]$.

\section{Yeast two-hybrid screen}

A human thymus cDNA library was screened for FOXP3 binding partners. The bait plasmid contained the full length FOXP3 sequence in-frame with the Gal4 DNA binding domain (BD). The prey plasmids contained human thymus library cDNA clones adjacent to the Gal4 activation domain (AD). cDNA clones were amplified using random primers and oligo $(\mathrm{dT})$ primers to generate partial and full-length cDNA clones, respectively. Interaction between the DNA-BD and AD permits transcription of reporters for histidine (His), adenine (Ade), and $\beta$-galactosidase $(\beta$-gal) synthesis. His-/Ade-dropout media and blue/white screening for $\beta$-gal activity permitted selection of clones containing FOXP3 interacting partners. Another level of selection criteria was provided by increasing doses of the histidine production inhibitor, 3-Amino-1,2,4-triazole (3-AT).

\section{Mouse Siva gene expression analysis based on microarray data}

We used microarray data from Fontenot et al. [33] to determine Siva expression levels in mouse T cell subsets. Accordingly, CD $4^{\text {pos }} \mathrm{T}$ cells from the Foxp $3^{G F P}$ mouse were sorted based on Foxp $3^{\mathrm{GFP}}$ and CD25 surface expression. The dataset, "CD4+ T cells expressing transcription factor Foxp3 and various amounts of CD25" (GDS1113 record), was accessed through NCBI's GEO database [59].

The Affymetrix Mouse Genome 4302.0 array used in this study includes four spots representing Siva. Each spot contains 11 probes. In order to determine which spots were likely to reveal the most accurate Siva gene expression profile, we investigated where each individual probe aligned to the mouse genome. We accessed the UCSC genome browser via the NetAff ${ }^{\mathrm{TM}}$ Analysis Center and observed probe alignment locations throughout the mouse genome. A few probes aligned to regions outside of the Siva coding region on chromosome 12 . We determined the ratio of correct to incorrect probe alignments (\# of Siva-aligning probes/\# of probes aligning to non-Siva regions) and discarded spots with a ratio less than 2 . The spots shown in this report, 1426323_X_AT and 1452020_A_AT, exhibited ratios of 3 and 7, respectively.

\section{T transfections, Co-IPs, and antibodies}

$293 \mathrm{~T}$ cells were co-transfected with Effectene according to the manufacturer's protocol (Qiagen). $4 \mu \mathrm{g}$ total plasmid DNA was added to sub-confluent cells in $10-\mathrm{cm}$ dishes. At 48-hours post-transfection, lysates were harvested in PBS, washed once and stored at $-20^{\circ}$. Cell pellets were lysed in modified RIPA (Tris- $\mathrm{HCl}, \mathrm{pH} 7.35,50 \mathrm{mM} ; \mathrm{NaCl}$, 150 mM; EDTA, 1 mM; NP-40 1\%; NaDeoxycholate 0.25\%) supplemented with Complete EDTA-free Protease Inhibitor (PI, Roche), phenylmethylsulfonyl fluoride (PMSF, $100 \mathrm{mM}$ ), and sodium fluoride (NaF, $50 \mathrm{mM}$ ). Immunoprecipitations (IPs) were performed in $\sim 1 \mathrm{ml}$ total volume PBS (supplemented with PI, PMSF and NaF). $500 \mu \mathrm{g}$ protein lysate and $40 \mu \mathrm{l}$ mouse anti-Myc 9E10 hybridoma supernatant (kindly provided by Dr. Yue Xiong) were added to PBS. The protein lysate comprised $5-10 \%$ of the IP volume. IPs were incubated on a rotator at $4^{\circ}$ overnight. Inputs were mixed with SDS loading dye and stored at $4^{\circ}$. A 1:1 mixture of Immobilized Protein A (Invitrogen) and Protein G Agarose (ThermoScientific) beads was prepared and washed three times with PBS. $40 \mu \mathrm{l}$ of bead mixture were added to each IP. IPs with beads were incubated $2-4$ hours at $4^{\circ}$ on a rotator. Beads were washed four times with cold PBS (no supplements). Washed beads were resuspended in $20 \mu \mathrm{l}$ SDS loading dye and heated to boiling in a $95^{\circ}$ sand bath ( 10 minutes). Boiled samples were run on $10 \%$ NuPage minigels according to the manufacturer's instructions (Invitrogen). Following transfer, PVDF membranes were blocked with PBS-Tween (0.2\% Tween, 5\% milk), which was used for all subsequent antibody incubation steps. Membranes were incubated with mouse $\alpha$-GFP (Clontech, Living Colors A. v. Monoclonal Antibody (JL-8), $100 \mathrm{ng} / \mathrm{ml}$ ) to detect immunoprecipitation of EGFP/Siva fusion constructs. Membranes were stripped and reprobed with rabbit $\alpha$ Myc sera (Also, provided by Dr. Yue Xiong).

\section{Standard RT PCR and quantitative PCR}

The Qiagen RNeasy isolation kit was used to isolate mRNA from frozen cell pellets preserved at $-80^{\circ}$ in Qiagen RLT buffer containing $\beta$-mercaptoethanol. Reverse transcription reactions were performed with random primers and M-MLV reverse transcriptase in the presence of RNase inhibitor. The following primer sequences were used in semi-quantitative RT PCRs: Siva For, 5'- TAC AGCTCAAGGTCCGCGTGA GC-3', Siva Rev, 5'-TCAC TGCAGTCCACGAGGCCACA-3', $\beta$-actin For, 5'- TCA CCCACACTGTGCCCATCTACGA-3', $\beta$-actin Rev, 5'CAG CGGAACCGCTCAT TGCCAATGG-3'. Quantitative Taq-Man PCR was performed using primers from Applied Biosystems. For 18S PCRs, cDNA templates were diluted 1:1000. Relative quantities were determined by correlating $\mathrm{C}_{\mathrm{T}}$ values to a standard curve. Relative Siva quantities were normalized to the relative $18 S$ quantity. 


\section{Retrovirus production and transduction}

Retroviral (RV) and lentiviral (LV) supernatants (SN) were produced by using the calcium phosphate method to transfect 293T cells with pHSPG, VSV-G, and gag/pol plasmids [60]. SN's were collected at 48 and 72 hours and titered on Jurkat cells by spinoculation, as has been described [56]. Efficiency of infectivity was determined based on \%GFP expression using a Gauva EasyCyte flow cytometer. For subsequent experiments, the \%-infected was used to calculate the volume of RV SN needed to obtain $99 \%$ transduction efficiency for a fixed cell number. Dual transductions with pHSPG-Siva-1 and pHSPGFOXP3 RV were performed as follows. A fixed number of cells was transduced with either pHSPG or pHSPGSiva-1 on day 0 . Two days later, high transduction efficiency was confirmed, the cells were counted and equal cell numbers were distributed and mixed with RV for either pHSPG or pHSPG-FOXP3. Since both sets of RV use GFP to mark transduction efficiency, GFP ${ }^{\text {neg }}$ Jurkat cells were transduced in parallel to control for transduction efficiency.

In Siva KD experiments, Jurkat T cells were transduced with pLKO-shEGFP or pLKO-shSiva LV and selected in puromycin (see Cell culture and plasmids above). Next, the same cells were transduced with PG or PG-FOXP3 RV.

\section{IL-2 ELISA}

To evaluate endogenous IL-2, transduced Jurkat T cells were distributed in 96-well plates at a concentration of $2 \times$ $10^{5}$ cells/well. Cells were activated with phorbol 12-myristate 13-acetetate (PMA, $25 \mathrm{ng} / \mathrm{ml})$ and Ionomycin $(1 \mu \mathrm{M})$. At the end of $\sim 18$ hours, cell viability was evaluated on a Gauva EasyCyte. Plates were spun down and supernatants were collected and stored at $-20^{\circ}$. IL-2 concentrations were determined with a BD OptEIA ${ }^{\mathrm{TM}}$ Human IL-2 ELISA kit.

\section{Jurkat transfections and luciferase reporter assays}

In order to perform luciferase assays, Jurkat cells were transfected by electroporation in cytomix buffer [61]. Jurkat cells were harvested, counted and redistributed to yield $5 \times 10^{6}$ cells/transfection. Cells were washed once in PBS before being suspended in cytomix buffer supplemented with fresh $2 \mathrm{mM}$ ATP (300 $\mu$ l buffer/transfection). While cells were being washed, plasmid DNA was prepared: $1 \mu \mathrm{g}$ reporter plasmid (see Cell culture and plasmids above) was mixed with differing amounts of plasmid expressing genes of interest or the vector control $(10 \mu \mathrm{g}$ DNA total). Cells in cytomix buffer were mixed with DNA mixtures and transferred to cuvettes on ice (Biorad Gene Pulser Cuvette, $0.4 \mathrm{~cm}$ ). A Biorad Gene Pulser Xcell was used to electroporate cells at $300 \mathrm{~V}, 500 \mu \mathrm{F}$, and infinite resistance. Immediately following electroporation of all samples, the shocked cells were diluted in pre-warmed culture media (RPMI 10\% FBS described above). Cells were cultured in 6-well plates. After resting for 12-24 hours, cells were distributed into 96-well plates and activated with PMA, $25 \mathrm{ng} / \mathrm{ml}$ and ionomycin, $1 \mu \mathrm{M}$. Duration of activation ranged from 6-12 hours. At the assay endpoint, $20 \mu \mathrm{l} /$ well was removed to measure viability and transfection efficiency on a Gauva EasyCyte mini flow cytometer. Plates were spun and cells were washed once with PBS to remove growth media. Cells were lysed in $45 \mu \mathrm{l} 1 \times$ Promega Reporter Lysis Buffer and frozen at $-80^{\circ}$. Plates were read on a Veritas Microplate Luminometer according to the manufacturer's instructions. The amount of promoter-driven reporter activity was expressed as a measure of relative light units (RLUs).

\section{Statistical analysis}

A two-tailed Student's t-test was used to evaluate statistical difference between experimental treatments and a $\mathrm{p}$-value $<0.05$ was set as the cut-off for statistically significant difference.

\section{Acknowledgements}

We thank Robert Hales, DO and Dr. William Ince for performing the yeast two-hybrid screen for FOXP3 binding partners. We thank Dr. Derek Holmes and Dr. Stephanie Mackey-Cushman for creating some of the FOXP3 truncation plasmids used in this study. This work was supported by a grant from the National Institutes of Health.

\section{Author details}

'Lineberger Comprehensive Cancer Center, School of Medicine, The University of North Carolina at Chapel Hill, Chapel Hill, NC 27599, USA. ${ }^{2}$ Department of Microbiology and Immunology, School of Medicine, The University of North Carolina at Chapel Hill, Chapel Hill, NC 27599, USA. ${ }^{3}$ Curriculum in Genetics and Molecular Biology, School of Medicine, The University of North Carolina at Chapel Hill, Chapel Hill, NC 27599, USA.

\section{Authors' contributions}

All experimental procedures leading to figures contained within were carried out by VKH. Both authors read and approved the final manuscript.

Received: 13 May 2011 Accepted: 28 September 2011

Published: 28 September 2011

\section{References}

1. Feuerer M, Hill JA, Mathis D, Benoist C: Foxp3+ regulatory T cells: differentiation, specification, subphenotypes. Nat Immunol 2009, 10(7):689-695.

2. Ziegler SF: FOXP3: of mice and men. Annu Rev Immunol 2006, 24:209-226.

3. Wildin RS, Ramsdell F, Peake J, Faravelli F, Casanova JL, Buist N, LevyLahad E, Mazzella M, Goulet O, Perroni L, et al: X-linked neonatal diabetes mellitus, enteropathy and endocrinopathy syndrome is the human equivalent of mouse scurfy. Nat Genet 2001, 27(1):18-20.

4. Bennett CL, Christie J, Ramsdell F, Brunkow ME, Ferguson PJ, Whitesell L, Kelly TE, Saulsbury FT, Chance PF, Ochs HD: The immune dysregulation, polyendocrinopathy, enteropathy, X-linked syndrome (IPEX) is caused by mutations of FOXP3. Nat Genet 2001, 27(1):20-21.

5. Kobayashi I, Shiari R, Yamada M, Kawamura N, Okano M, Yara A, Iguchi A, Ishikawa N, Ariga T, Sakiyama Y, et al: Novel mutations of FOXP3 in two Japanese patients with immune dysregulation, polyendocrinopathy, enteropathy, X linked syndrome (IPEX). J Med Genet 2001, 38(12):874-876. 
6. Zuo T, Liu R, Zhang H, Chang X, Liu Y, Wang L, Zheng P: FOXP3 is a novel transcriptional repressor for the breast cancer oncogene SKP2. J Clin Invest 2007, 117(12):3765-3773.

7. Zuo T, Wang L, Morrison C, Chang X, Zhang H, Li W, Liu Y, Wang Y, Liu X, Chan MW, et al: FOXP3 is an X-linked breast cancer suppressor gene and an important repressor of the HER-2/ErbB2 oncogene. Cell 2007, 129(7):1275-1286

8. Marson A, Kretschmer K, Frampton GM, Jacobsen ES, Polansky JK, Maclsaac KD, Levine SS, Fraenkel E, von Boehmer H, Young RA: Foxp3 occupancy and regulation of key target genes during T-cell stimulation. Nature 2007, 445(7130):931-935

9. Hill JA, Feuerer M, Tash K, Haxhinasto S, Perez J, Melamed R, Mathis D, Benoist C: Foxp3 transcription-factor-dependent and -independent regulation of the regulatory $\mathrm{T}$ cell transcriptional signature. Immunity 2007, 27(5):786-800.

10. Holmes D, Knudsen G, Mackey-Cushman S, Su L: FoxP3 enhances HIV-1 gene expression by modulating NFkappaB occupancy at the long terminal repeat in human T cells. J Biol Chem 2007, 282(22):15973-15980

11. Li B, Samanta A, Song X, lacono KT, Brennan P, Chatila TA, Roncador G, Banham AH, Riley JL, Wang $Q$, et al: FOXP3 is a homo-oligomer and a component of a supramolecular regulatory complex disabled in the human XLAAD/IPEX autoimmune disease. Int Immunol 2007, 19(7):825-835.

12. Zhou Z, Song X, Li B, Greene MI: FOXP3 and its partners: structural and biochemical insights into the regulation of FOXP3 activity. Immunol Res 2008, 42(1-3):19-28.

13. Bettelli $E$, Dastrange $M$, Oukka M: Foxp3 interacts with nuclear factor of activated T cells and NF-kappa B to repress cytokine gene expression and effector functions of T helper cells. Proc Natl Acad Sci USA 2005, 102(14):5138-5143.

14. Li B, Samanta A, Song X, lacono KT, Bembas K, Tao R, Basu S, Riley JL, Hancock WW, Shen Y, et al: FOXP3 interactions with histone acetyltransferase and class II histone deacetylases are required for repression. Proc Natl Acad Sci USA 2007, 104(11):4571-4576.

15. Ono M, Yaguchi H, Ohkura N, Kitabayashi I, Nagamura Y, Nomura $T$, Miyachi Y, Tsukada T, Sakaguchi S: Foxp3 controls regulatory T-cell function by interacting with AML1/Runx1. Nature 2007, 446(7136):685-689

16. Lee SM, Gao B, Fang D: FoxP3 maintains Treg unresponsiveness by selectively inhibiting the promoter DNA-binding activity of AP-1. Blood 2008, 111(7):3599-3606.

17. Du J, Huang C, Zhou B, Ziegler SF: Isoform-specific inhibition of ROR alpha-mediated transcriptional activation by human FOXP3. I Immunol 2008, 180(7):4785-4792.

18. Ichiyama K, Yoshida H, Wakabayashi $Y$, Chinen T, Saeki K, Nakaya M, Takaesu G, Hori S, Yoshimura A, Kobayashi T: Foxp3 inhibits RORgammatmediated IL-17A mRNA transcription through direct interaction with RORgammat. J Biol Chem 2008, 283(25):17003-17008.

19. Zhou L, Lopes JE, Chong MM, Min R, Victora GD, Shen Y, Du J, Rubtsov YP, Rudensky AY, et al: TGF-beta-induced Foxp3 inhibits $\mathrm{T}(\mathrm{H}) 17$ cell differentiation by antagonizing RORgammat function. Nature 2008, 453(7192):236-240

20. Pan F, Yu H, Dang EV, Barbi J, Pan X, Grosso JF, Jinasena D, Sharma SM, McCadden EM, Getnet D, et al: Eos mediates Foxp3-dependent gene silencing in CD4+ regulatory T cells. Science 2009, 325(5944):1142-1146.

21. Chae WJ, Henegariu O, Lee SK, Bothwell AL: The mutant leucine-zipper domain impairs both dimerization and suppressive function of Foxp3 in T cells. Proc Natl Acad Sci USA 2006, 103(25):9631-9636

22. Wu Y, Borde M, Heissmeyer V, Feuerer M, Lapan AD, Stroud JC, Bates DL, Guo L, Han A, Ziegler SF, et al: FOXP3 controls regulatory T cell function through cooperation with NFAT. Cell 2006, 126(2):375-387.

23. Ma A, Koka R, Burkett P: Diverse functions of IL-2, IL-15, and IL-7 in lymphoid homeostasis. Annu Rev Immunol 2006, 24:657-679.

24. Malek TR, Bayer AL: Tolerance, not immunity, crucially depends on IL-2. Nat Rev Immunol 2004, 4(9):665-674

25. Hori S, Nomura T, Sakaguchi S: Control of regulatory T cell development by the transcription factor Foxp3. Science 2003, 299(5609):1057-1061

26. Schubert LA, Jeffery E, Zhang $Y$, Ramsdell F, Ziegler SF: Scurfin (FOXP3) acts as a repressor of transcription and regulates $\mathrm{T}$ cell activation. $J$ Biol Chem 2001, 276(40):37672-37679.
27. Prasad KV, Ao Z, Yoon Y, Wu MX, Rizk M, Jacquot S, Schlossman SF: CD27, a member of the tumor necrosis factor receptor family, induces apoptosis and binds to Siva, a proapoptotic protein. Proc Natl Acad Sci USA 1997, 94(12):6346-6351.

28. Yoon Y, Ao Z, Cheng Y, Schlossman SF, Prasad KV: Murine Siva-1 and Siva2, alternate splice forms of the mouse Siva gene, both bind to CD27 but differentially transduce apoptosis. Oncogene 1999, 18(50):7174-7179.

29. Spinicelli S, Nocentini G, Ronchetti S, Krausz LT, Bianchini R, Riccardi C: GITR interacts with the pro-apoptotic protein Siva and induces apoptosis. Cell Death Differ 2002, 9(12):1382-1384.

30. Croft M: Co-stimulatory members of the TNFR family: keys to effective Tcell immunity? Nat Rev Immunol 2003, 3(8):609-620.

31. Ruprecht CR, Gattorno M, Ferlito F, Gregorio A, Martini A, Lanzavecchia A, Sallusto F: Coexpression of CD25 and CD27 identifies FoxP3+ regulatory T cells in inflamed synovia. J Exp Med 2005, 201(11):1793-1803.

32. Koenen HJ, Smeets RL, Vink PM, van Rijssen E, Boots AM, Joosten I: Human CD25highFoxp3pos regulatory T cells differentiate into IL-17-producing cells. Blood 2008, 112(6):2340-2352

33. Fontenot JD, Rasmussen JP, Williams LM, Dooley JL, Farr AG, Rudensky AY: Regulatory $T$ cell lineage specification by the forkhead transcription factor foxp3. Immunity 2005, 22(3):329-341.

34. Arch RH: Function of tumor necrosis factor receptor family members on regulatory T-cells. Immunol Res 2005, 32(1-3):15-29.

35. Ko K, Yamazaki S, Nakamura K, Nishioka T, Hirota K, Yamaguchi T, Shimizu J, Nomura T, Chiba T, Sakaguchi S: Treatment of advanced tumors with agonistic anti-GITR mAb and its effects on tumor-infiltrating Foxp3 +CD25+CD4+ regulatory T cells. J Exp Med 2005, 202(7):885-891.

36. Gudi R, Barkinge J, Hawkins S, Chu F, Manicassamy S, Sun Z, DukeCohan JS, Prasad KV: Siva-1 negatively regulates NF-kappaB activity: effect on T-cell receptor-mediated activation-induced cell death (AICD). Oncogene 2006, 25(24):3458-3462.

37. Xue L, Chu F, Cheng Y, Sun X, Borthakur A, Ramarao M, Pandey P, Wu M, Schlossman SF, Prasad KV: Siva-1 binds to and inhibits BCL-X(L)-mediated protection against UV radiation-induced apoptosis. Proc Natl Acad Sci USA 2002, 99(10):6925-6930.

38. Kim HP, Imbert J, Leonard WJ: Both integrated and differential regulation of components of the IL-2/IL-2 receptor system. Cytokine Growth Factor Rev 2006, 17(5):349-366.

39. Crispin JC, Tsokos GC: Transcriptional regulation of IL-2 in health and autoimmunity. Autoimmun Rev 2009, 8(3):190-195.

40. Mitchell T, Sugden B: Stimulation of NF-kappa B-mediated transcription by mutant derivatives of the latent membrane protein of Epstein-Barr virus. J Virol 1995, 69(5):2968-2976.

41. Northrop JP, Ullman KS, Crabtree GR: Characterization of the nuclear and cytoplasmic components of the lymphoid-specific nuclear factor of activated T cells (NF-AT) complex. J Biol Chem 1993, 268(4):2917-2923.

42. Nestler M, Martin U, Hortschansky P, Saluz HP, Henke A, Munder T: The zinc containing pro-apoptotic protein siva interacts with the peroxisomal membrane protein pmp22. Mol Cell Biochem 2006, 287(1-2):147-155.

43. Lin FT, Lai YJ, Makarova N, Tigyi G, Lin WC: The lysophosphatidic acid 2 receptor mediates down-regulation of Siva-1 to promote cell survival. $J$ Biol Chem 2007, 282(52):37759-37769.

44. Py B, Bouchet J, Jacquot G, Sol-Foulon N, Basmaciogullari S, Schwartz O, Biard-Piechaczyk M, Benichou S: The Siva protein is a novel intracellular ligand of the CD4 receptor that promotes HIV-1 envelope-induced apoptosis in T-lymphoid cells. Apoptosis 2007, 12(10):1879-1892.

45. Mihatsch K, Nestler M, Saluz HP, Henke A, Munder T: Proapoptotic protein Siva binds to the muscle protein telethonin in cardiomyocytes during coxsackieviral infection. Cardiovasc Res 2009, 81(1):108-115.

46. Lopes JE, Torgerson TR, Schubert LA, Anover SD, Ocheltree EL, Ochs HD, Ziegler SF: Analysis of FOXP3 reveals multiple domains required for its function as a transcriptional repressor. J Immunol 2006, 177(5):3133-3142.

47. Viatour P, Merville MP, Bours V, Chariot A: Phosphorylation of NF-kappaB and IkappaB proteins: implications in cancer and inflammation. Trends Biochem Sci 2005, 30(1):43-52

48. Py B, Slomianny C, Auberger P, Petit PX, Benichou S: Siva-1 and an alternative splice form lacking the death domain, Siva-2, similarly induce apoptosis in T lymphocytes via a caspase-dependent mitochondrial pathway. J Immunol 2004, 172(7):4008-4017. 
49. Balci-Peynircioglu B, Waite AL, Hu C, Richards N, Staubach-Grosse A, Yilmaz E, Gumucio DL: Pyrin, product of the MEFV locus, interacts with the proapoptotic protein, Siva. J Cell Physiol 2008, 216(3):595-602.

50. Shuyu E, Lai YJ, Tsukahara R, Chen CS, Fujiwara Y, Yue J, Yu JH, Guo H, Kihara A, Tigyi G, et al: Lysophosphatidic acid 2 receptor-mediated supramolecular complex formation regulates its antiapoptotic effect. $J$ Biol Chem 2009, 284(21):14558-14571.

51. Cottle DL, McGrath MJ, Wilding BR, Cowling BS, Kane JM, D'Arcy CE, Holdsworth M, Hatzinisiriou I, Prescott M, Brown S, et al: SLIMMER (FHL1B/ KyoT3) interacts with the proapoptotic protein Siva-1 (CD27BP) and delays skeletal myoblast apoptosis. J Biol Chem 2009, 284(39):26964-26977.

52. Cao C, Ren X, Kharbanda S, Koleske A, Prasad KV, Kufe D: The ARG tyrosine kinase interacts with Siva-1 in the apoptotic response to oxidative stress. J Biol Chem 2001, 276(15):11465-11468.

53. Henke A, Nestler M, Strunze S, Saluz HP, Hortschansky P, Menzel B, Martin $U$, Zell R, Stelzner A, Munder T: The apoptotic capability of coxsackievirus B3 is influenced by the efficient interaction between the capsid protein VP2 and the proapoptotic host protein Siva. Virology 2001, 289(1):15-22.

54. Chu F, Borthakur A, Sun X, Barkinge J, Gudi R, Hawkins S, Prasad KV: The Siva-1 putative amphipathic helical region (SAH) is sufficient to bind to $\mathrm{BCL}-\mathrm{XL}$ and sensitize cells to UV radiation induced apoptosis. Apoptosis 2004, 9(1):83-95.

55. Heckman KL, Pease LR: Gene splicing and mutagenesis by PCR-driven overlap extension. Nat Protoc 2007, 2(4):924-932.

56. Coffield VM, Helms WS, Jiang Q, Su L: Galpha13 mediates a signal that is essential for proliferation and survival of thymocyte progenitors. J Exp Med 2004, 200(10):1315-1324

57. Vitriol EA, Uetrecht AC, Shen F, Jacobson K, Bear JE: Enhanced EGFPchromophore-assisted laser inactivation using deficient cells rescued with functional EGFP-fusion proteins. Proc Natl Acad Sci USA 2007, 104(16):6702-6707.

58. Guttridge DC, Albanese C, Reuther JY, Pestell RG, Baldwin AS Jr: NF-kappaB controls cell growth and differentiation through transcriptional regulation of cyclin D1. Mol Cell Biol 1999, 19(8):5785-5799.

59. Edgar R, Domrachev M, Lash AE: Gene Expression Omnibus: NCBI gene expression and hybridization array data repository. Nucleic Acids Res 2002, 30(1):207-210.

60. Pear WS, Nolan GP, Scott ML, Baltimore D: Production of high-titer helperfree retroviruses by transient transfection. Proc Natl Acad Sci USA 1993, 90(18):8392-8396.

61. van den Hoff MJ, Moorman AF, Lamers WH: Electroporation in 'intracellular' buffer increases cell survival. Nucleic Acids Res 1992, 20(11):2902.

doi:10.1186/1471-2172-12-54

Cite this article as: Hench and Su: Regulation of $I L-2$ gene expression by Siva and FOXP3 in human T cells. BMC Immunology 2011 12:54.

\section{Submit your next manuscript to BioMed Central and take full advantage of:}

- Convenient online submission

- Thorough peer review

- No space constraints or color figure charges

- Immediate publication on acceptance

- Inclusion in PubMed, CAS, Scopus and Google Scholar

- Research which is freely available for redistribution

Submit your manuscript at www.biomedcentral.com/submit
Biomed Central 